\title{
Streaming into the Void: An Analysis of Microstreaming Trends and Behaviors Utilizing a Demand Framework
}

\author{
Andrew M. Phelps \\ University of Canterbury (and) \\ American University \\ HIT Lab NZ (and) AU Game Lab \\ Christchurch, New Zealand (and) \\ Washington, DC, USA \\ andymphelps@gmail.com
}

\author{
Mia Consalvo \\ Concordia University \\ Department of Communication \\ Studies \\ Montreal, Quebec, Canada \\ mconsalvo@gmail.com
}

\author{
Nick D. Bowman \\ Texas Tech University \\ College of Media and \\ Commnication \\ Lubbock, Texas, USA \\ nick.bowman@ttu.edu
}

\begin{abstract}
This work introduces the concept of 'microstreaming' to describe individuals who livestream their hobbies to small audiences for little to no financial reward. Much research into streaming focuses on revenue and transactional costs from a labor/playbor perspective, but such approaches do not completely capture the largely intrinsic typical of 'microstreamers.' Recent research into microstreamers employing a range of methods across observational and laboratory settings pointed to a range of cognitive, emotional, physical, and social demands reportedsome that detracted from and some that enhanced the experience. These examples suggest that a demand framework is another important model for examining microstreamers, which has implications for understating microstreaming behaviors and experiences across multiple platforms and interactions.
\end{abstract}

\section{Introduction}

One of the most engaging, interesting, and largest trends in internet behavior over the past few years has been the phenomenon of livestreaming. Although not an activity exclusive to video games, nearly nine in 10 streams on platforms such as Twitch.tv are dedicated to game streaming, as are the 50 most-viewed streams on the platform. Most related academic work has focused on the largest streams and streamer personalities, and how streamers accrue status, followers, and resources [1], as well as the relationship between streaming and esports [2][3].

Yet for every large stream with hundreds or thousands of viewers, there is a long trail of streams with average audience sizes approaching zero. Such streamers have been labelled 'microstreamers' and research about them is just starting to emerge [4]. Recognizing the diversity among microstreamers uses of and motivation for their streaming, we define microstreamers as those (a) with small streaming audiences and (b) who do not earn a living wage from their streaming. In this definition, "micro" refers to the audience sizes typical of their streams (defining small as having fewer than 100 concurrent viewers), and describes an activity that is considered intrinsically (e.g., motivated by personal or social interest) rather than extrinsically motivating (e.g., for profit or status; [5]); we do not consider the relative amount of time one spends streaming in this definition. Moreover, microstreaming is not an activity tied to any one streaming platform (i.e., Twitch) or activity (such as video games), as streaming content has diversified in recent years to include sharing one's computer programming, art creation, cooking, and chatting with friends amongst many other activities.

For many microstreamers, their streaming activity is a mediated extension of their personal leisure activities. While several scholars have examined aspects of streaming (including microstreaming without necessarily making this distinction) through a lens of labor/playbor with important findings such as Johnson \& Woodcock [6] (with respect to livestreaming more generally), Ruberg [7] (with respect to gender and streaming), and Partin [8] and Walker [9] (with respect to labor as related to streaming and surveillance), it is also the case that streaming is often read as labor in a primarily economic sense -i.e. as a pathway where success as a streamer is focused around audience growth and monetization - and this narrative is structurally reinforced and platformitized in environments such as Twitch via platform based currencies, audience metrics, status ladders, gamification elements, etc. To this end, we do not suggest that microstreamers have no ambitions towards larger and monetized streams nor that labor concerns are not applicable to microstreaming. However, we assert that their activity appears to be driven more by (a) an innate interest in the activity being 
streamed and (b) a motivation to share that activity with (a few) others.

Despite their prevalence, microstreamers tend to be overlooked by scholars [10]. Likewise, existing theoretical frameworks for understanding streaming largely rely on theories of labor and compensation, as noted previously, and how streaming platforms are exploiting this segment of their users (e.g., [6]). However, such a framework can be problematic for wholly explaining microstreamers, as these individuals rarely consider, depict, or describe their own activities as 'labor' per se. While surely a wider examination of labor in the context of relational labor [11], aspirational labor [12], the labor of visibility [13], and the labor of glamor [14] can help inform and color the nuances of observable microstreaming behavior, this does not solve the issue that, as Stevens writes "[through] efforts to distinguish conceptually between what is 'play' and what is 'work,' we have gotten ourselves into a rut" [15]. Thus, we examine microstreaming through a lens outside these discussions, even if individual or specific actions of microstreamers might still be interpreted as labor, in order to better understand additional elements and/or motivations that may not be fully captured via a labor-based analysis. We recognize that microstreamers may both (a) experience some motivations similar to their professional counterparts and yet (b) might feel others as well. To this end, we borrow the interactivityas-demand framework [16][17] to explain some of the motivations of microstreamers.

\section{Theoretical Framework}

When studying interactive media, it is important to understand the implicit demands that these media place on their users. If we understand interactivity as the user's relative agency over the form or content of onscreen portrayals [18], the other side of this is that users are required to enact some agency over the experience - in a very real sense, all interactive media involves some level of co-production [19] or coauthorship [20].

At least four such requirements, or demands, have been identified in prior research: (1) cognitive demand associated with making sense of systems ("a requirement to think"), (2) emotional demands associated with basic and complex affective reactions to events in a system (a "requirement to feel"), (3) physical demands associated with the tactile or haptic inputs required to operate a system (a "requirement to act") and (4) social demands associated with engaging other social actors (a "requirement to mingle"; [16][17]).

Microstreaming maps to each of the four types of demand specified in this model: (1) cognitive demand, as streaming requires both interpretation and rationalization of the stream's content including its associated chat, glyphs, messages, and community engagement, (2) emotional demand, both in terms of dealing with videogame content itself and in reaction to interpersonal emotions that arise from gameplay as well as both community involvement (or lack thereof), (3) physical demand, both in terms of the dexterity and physical actions associated with streaming as well as the ways the platform incentivizes long hours of engagement, and (4) social demand, as streamers seek (sometimes unsuccessfully) to cultivate community engagement and interaction with their stream, and intersect with numerous other networks.

\section{Observations of Microstreamers in Practice}

To elaborate and expand on this interactivity-asdemand framework and its utility for better understanding microstreaming activities, this paper draws from data gathered from three separate studies of smaller scale livestreaming activities, outlined below. One study is a multi-year digital ethnography of microstreamers, observing and interviewing dozens of individuals about their streaming practices, as well as observing how their streams have persisted (or not) over time. Another study engaged in a six-month review of 27 different 'art streamers' focused on the creation of two-dimensional artworks, either physically or digitally. A third study used experimental designs to assign gamers to stream a first-person shooter either synchronously (live) or asynchronously (recorded for later upload) to micro audiences (e.g., two spectators). Collectively, these studies were chosen as they illustrate (a) ethnographic findings from a population of gamecentered streamers, (b) findings from a population that is not directly game-oriented, and (c) comparable laboratory findings that seek to replicate or refute some of the observed behaviors from the ethnographic work. Where possible, we identify how each study's findings could be usefully understood (or reinterpreted) via this framework. We also distinguish how demands might be particularly unique or relevant for microstreamers.

\subsection{Ethnographic Study of Microstreamers}

The first study to be discussed here began as an effort to better understand microstreamers who are members of marginalized populations, and in particular those who streamed a variety of games rather than a single eSport title. This entailed a multi-year observation of hundreds of hours of streams from around the world, trying to zero in on female or non- 
binary individuals, streamers of color, queer folks, older streamers, those with disabilities, as well as any other 'non-dominant' type of streamer we could identify [4]. To our dismay, many of the most popular variety streamers were consistently within the default demographic mentioned above, and so we began to cast a wider net, moving to smaller streams. Upon extended viewing we became more and more interested in those streaming at the 'micro' scale. Many were not distinguishable in terms of their 'quality' compared to more popular streamers, although as we went to smaller and smaller audiences that did change somewhat. But we also then noticed key differences in how microstreamers managed the particular challenges of having very small-or no-audiences watching them. Those observations led to a second phase of research that included more than 40 in-depth interviews, recruiting specifically for streamers with smaller audiences. We did do a handful of interviews with very popular, highly viewed streamers, but that was mainly to compare their experiences and practices with the microstreamers.

One consequence of this emerging focus on smaller streamers was an increasingly ill fit with a simple 'labor theory' explanation of their activities as previously discussed at length, and we began to search for other ways of understanding their streaming. One framework we employed was from leisure studies, to distinguish those who approached streaming from a 'serious leisure' perspective as opposed to a more 'casual' approach [21]. Here, we propose an additional framework for their activities that also helps games scholars move beyond labor and work as primary ways to understand streaming, and to push scholars to seek multiple frameworks and disciplinary approaches in their work. To do this, each type of demand is briefly explained and explored via data from this project.

\subsubsection{Cognitive Demands of Microstreaming}

As defined above, we can explain the cognitive demand from streaming as that activity which requires both interpretation and rationalization of the stream's content including its associated chat, glyphs, messages, and community engagement, as well as constant engagement with gameplay itself. From an examination of streamers' descriptions of their activities, we can easily see multiple dimensions to cognitive activities in streaming. As Fahmay confirmed, a key part of the challenge is simply learning to pay attention to alerts and chat while also playing a game at the same time. Seriously Clara elaborates "my attention is split between playing the game, making non-stop entertaining commentary, reading and responding to chat, responding to alerts, social media, and little fires that need to be put out." Once microstreamers have become adept at the basics, though, very few stop there, and instead continue to layer new elements onto or into their streams, which likewise require learning new skills as well as weighing their benefits/costs ratio.

This is particularly important if microstreamers want to grow their streaming audience or perhaps even retain them. Nickeedee reported he "made a point of getting to know everyone [in his stream]'s first name" while Skittzipoo took time to create and use a loyalty currency for her audience, and reports she is "always improving my screen layout" and adding elements such as allowing viewers to redeem fortune readings.

Depending on how finely grained streamers want to control their audience's chat, even more skills may be demanded. Kira, a streamer as well as moderator for other streamers explained that monitoring chat for offensive speech is not as simple as it seems. As she points out, "someone will say something and it seems racist, [but] is it? Do they mean it well, do they just phrase it poorly?" In response she is always trying to make judgment calls about how best to react. While Kira was making these decisions as a mod and could focus solely on that activity, streamers must balance that decision making while playing a game at the same time, suggesting multiple cognitive processes being balanced at once.

Many-but not all-microstreamers try to balance their own abilities and limitations against audience expectations, or the hope of future potential growth. Protomagicalgirl explained that her lack of ability to adhere to a streaming schedule likely inhibited her growth but was a result of her mental health being "garbage." More optimistically, CastarasKaelde preserves her own health by ending streams early if "I'm streaming and I find that I'm struggling to think of things to say and when that happens I know that I've run out of energy and should probably stop the stream soon." Her healthy attitude is most likely shaped by her focus on the activity as mainly a hobby, where "I'm generally doing the stream as a fun thing and not as a specific big thing ... I mainly focus on my real life before I focus on streaming."

\subsubsection{Emotional Demands of Microstreaming}

Even for microstreamers, the emotional demands of the activity can be multiple and varied. In addition to simply watching dozens of microstreamers react in joy, sadness, frustration and anger, many reported to us that the activity offers both highs and lows, regardless of whether or not they earn money from the activity or even take it seriously. Of course, happiness and satisfaction were common emotions, as this is a voluntary activity and it would be strange if it consistently only made people unhappy. Some streamers were very clear though, such as Gitsie, who 
reported that "streaming has made me feel really good about myself" which carried through into her streams, such as when she hit 1000 followers (but not concurrent viewers) and "I cried on stream, I ugly cried. I was full on crying and I was so appreciative."

This suggests that streamers aren't always in full control of their emotions, and can find themselves reliant on, or reflecting off, their audiences. This can be a very direct thing, as Adam Ziegler explained "my mood and energy changes depending on how many people I know are watching; like I'll be more laid back at the start but if I start getting more people in I'll try to jazz it up a little bit because it feels good to have a couple more people watching than usual." And as MegaMagWitch pointed out, streaming "is very [emotionally]draining" and so "if a stream isn't doing well then you can start to think that it is a reflection of your own worth."

\subsubsection{Physical Demands of Microstreaming}

At first blush the physical demands of streaming are not always obvious but are nonetheless important to investigate and understand. While not discussed in detail here, a primary demand relates to women who stream, and how they dress, apply makeup (or not), fix their hair, and place their webcams. Such routines can take nontrivial amounts of time and require managing one's physical appearance in ways that male streamers rarely must attend to. As Exalted Flower sums it up "a guy can look the way he does and no one will challenge his looks or his streams."

Across all streamers, however, we found that there is a physical toll that streaming can take on one's body after sitting for hours at a time. Additionally, microstreamers told us about 'micro-adjustments' they made to their physical appearances that seemed to build off from cognitive and emotional demands to perform (or mask) specific emotional states for their audiences.

Even for those not trying to make a living, the lure of engaging in long streams, sometimes $12+$ hours at a stretch, can be there. This could relate to a stream-a-thon tied to raising money for a charity, or simply to celebrate a personal milestone such as a birthday or streaming anniversary. Many smaller streamers do attempt such events, but often only once, or very infrequently. TheChaseLemon wanted to do a $12+$ hour sub-a-thon to gain followers which went on for 19 hours, but afterwards slept for 9.5 hours, did 'nothing' the next day, and then slept another 10 hours. As he admitted, those activities while fun "do take a toll" and so for him are fairly rare occurrences.

Streamers reported that they sometimes took great care to manage their facial expressions while streaming. This could be to avoid telegraphing disappointment they wished to hide, or to possibly avoid offending teammates they were actively playing with while streaming. Exalted Flower explained that when playing with others, if they get angry about the team's performance and blame her, "I'm just a lot quieter than normal and you can see it on my face that I don't want to be here anymore, so I'll try to end my stream and just get away from them." Similarly, Ryan Markel told us he "has to be a lot more intentional about my facial expressions in activities that involve other people. Sometimes I really want to roll my eyes but I just have to lock my vision, because that person might watch that video."

\subsubsection{Social Demands of Microstreaming}

Finally, individuals had many things to say related to the social demands of microstreaming, including well covered territory such as sexism and racism [22][23]), the amount of labor involved in managing the social side of one's stream as well as how to make audiences feel like communities [23]. This could be very specialized with some of the folks we interviewed, who for example saw their spaces as welcoming or safe spaces for marginalized groups in particular. For example, Protomagicalgirl saw her chat channel and Discord server as a way to give a younger group of trans individuals "a better shot" at feeling welcome. And for some streamers, the interactivity with their audience was "the primary focus" of why they did what they did, as MegaMagWitch related.

Yet as discussed previously, microstreamers can also feel the pressures of a lack of social interaction in their streamers, whether entirely or in various degrees. Shanbot felt that a low viewer count affects her performance, and similarly Zillanoises told us that when she started streaming "just interacting with people was a really big deal" because she didn't have any local friends at the time. The growth of a community on her stream - and the opportunity to make friends - made her feel like she was "getting to really feel like myself again." And microstreamers can face a particular dilemma in monitoring their growing communities for bad actors-being too strict leaves them with fewer viewers but being too lax means potential abuse. As Shnaff told us, he had some very bad early experiences with trolls as he first started streaming, and he began to fear any new individuals who showed up in his chat stream. This led to a tough situation where "sometimes I feared I'd be banning people the second they came in even though I'm trying to grow a new channel."

\subsection{Observational Study of Microstreamers Engaged in Art Streaming}

There is little academic work exploring art streaming despite its popularity and educational potential. 
Consalvo and Phelps provide an analysis of a professional art streamer [24] and compare that activity to a development streamer in the context of game creation. Building upon that work, Phelps and Consalvo note in a further study of the subject several relevant behaviors across a study of "approximately 280 [art] streamers" [25]. (We followed a similar methodology to their initial study, but only observed 27 additional streamers for this work over approximately six months.) Noted in their work are the motivations and goals of these streamers which are in keeping with our general definition of microstreamers, i.e. that the primary motivations are not necessarily financial or even rooted in the normalized goals of the platform with regard to monetization or audience aggregation. Yet their work uses as a framework a comparison to labor/playbor models common to game studies and provides a comparative analysis between common elements of art streaming and other forms of fan-based or player-based labor in games: modding, goldfarming, walkthroughs, and, of course, streaming and community monetization. We are not proposing that the labor of these streamers go unrecognized, but in our analysis this model does not capture some of the core motivational effort of the activity such that cognitive, emotional, physical, and social demand are understood in context.

\subsubsection{Cognitive Demands of Art Streaming}

The core motivation of the art streamers that we observed was, in essence, to become a better artist. In this context, the cognitive demand of the activity is intense as it directly engages the streamer not merely in the activity but in the simultaneous meta-examination of the activity: they are creating art, streaming that creative act, and constantly evaluating what they are learning and practicing as to whether the activity is actively enhancing their own skill. This applies not only to streamers but also to viewers: the "informal scaffolding" that Phelps and Consalvo describe where artists will "seek to associate with others producing work at a similar or slightly aspirational level" [25] implies that this is a key differentiator. While large game streams may be a way for gamers to observe new strategies or techniques, this is rarely described as the core objective. Coupled with this notion is also the cognitive demand of critique, both of self and/or others - one of the key traits in becoming a valuable member of the art streaming community is providing feedback and analysis to others, and this is commonly brokered amongst art microstreamers (i.e. 'watch my stream and I'll watch yours' for the express purpose of critique). Further, there is the cognitive demand of conjoining the activity of art creation itself with the performative aspect of streaming. This is not dissimilar to game-oriented streaming and takes many of the same forms (narration, personality as performance, etc.), but analyzing it as labor misses the way that these various layers of cognitive load intertwine.

\subsubsection{Emotional Demands of Art Streaming}

The area of emotional demand is one in which the divergence between reading art microstreaming as labor versus a demand framework is perhaps most apparent. In a labor frame, the primary goal of streaming activity is, generally, presented as growth of the stream along an axis meaningful to the streamer, be it financial (which is written about at length), or rooted in fame, popularity, notoriety, or other metrics. The common denominator here is that 'success' is evaluated in metrics that represent commercial interests either of the streamer or the platform itself, and in this way the entire activity can be read as a twist on the hedonic gratification of producing experiences to drive consumption, and or of consumption itself [26].

Yet the emotional meaningfulness of art-as-activity, particularly to its creator, often has very little to do with commercial concerns or metrics of nearly any form. The motivation to practice art is often described as intrinsic [27], and this motivation is then either sustained or crippled via issues of perceived competence over time [28]. The critical factor here is that art is often engaged in simply for the gratification of the act itself. Bob Ross, after all, titled his show The Joy of Painting [29], which was in many senses an early form of art streaming, albeit with much larger commercial aspirations and impact. (It is perhaps no accident that one of the more popular features of the Art channel on Twitch are weekend marathon viewings of recorded episodes of Ross' show [30]). In this sense, art streaming then, and particularly when conjoined with the notion of microstreaming, can be read as fulfilling basic psychological needs not through hedonic rationales but rather through eudaimonic gratification, fulfilling for the artist innate desires such as autonomy, competency, and relatedness [31]. In this context, failing to recognize the divergent goals between art microstreamers engaged in an activity that helps them to ritualize their practice but whom often choose not to engage with the commercial or growthfueled hedonic aspects of the platform and/or community, make labor a poor model for describing the totality of emotional motivation or demand of these communities.

\subsubsection{Physical Demands of Art Streaming}

The physical demands of art streaming are in some ways obvious: studio art takes time and practice, and this is directly incentivized by platforms such as Twitch that encourage ever longer streams and daily interaction. In addition, many art streamers employ additional technology to display not only their screens and 
webcams but also views of their hands or arms as they are engaged with physical media in drawing, painting, sculpture, or in digital media with drawing tablets, iPads, and more. But describing this as labor again seems at odds with the motivation for the activity, and, indeed, the joy of artistic expression. The microstreamers that we observed were nearly all casual artists -i.e. their activity was not their primary source of income (if it even provided income at all), and while a few were focused on the idea of one day being a professional artist, most were engaged with the activity because they were drawn to it, and a portion of that motivation is the physical demand of creating art with one's hands. While there are numerous areas in traditional fine art that might be described as physical labor (hanging a painting, building a frame, packing and unpacking pieces for a show, cleaning, etc.) it is rare that the actual artistic act itself-brush to canvas, fingers to clay, pastelle to paper-is read as labor in the same context. It is through the commercialization of art (and artist) that labor models are engaged, but these models do not capture the motivations for physical demand with the core activity: they focus on the stream but not the content, despite the fact they are conjoined.

\subsubsection{Social Demands of Art Streaming}

The social demands of art-centric microstreaming are perhaps the area with the most convergence with labor-based approaches. While there are some aspects of social demand within this community that are unique to the subject, many others are not, and it is these areas where the social demands diverge from the centrality of creative focus that seem most like traditional definitions of labor. Somewhat unique to art streaming and other creative channel activities is the need to socially construct and manage norms for feedback and critique: Phelps and Consalvo note that some artists specifically created times and discussion norms where feedback on the work was appropriate while limiting feedback during other portions of the creative process. Our own observations noted similar behaviors, including one streamer that wrote bots specifically to inform the chat channel of this duality at different times. Given the size of these streams, many of the participants appeared to know each other, and were engaged in a distributed form of a sort of 'digital 'artists commune' [32], looking to the collective group as a community of practice.

That said, numerous other social demands were present, and are typical of the larger streaming ecosystem. The representation of the artist on numerous competing and integrated platforms such as Twitter, Discord, Facebook, BeHance, Deviant Art and others [25] is a substantial amount of work that is disjoint from the actual creative activity. The toxicity of Twitch similarly detracts from the focus on core creative activity, and as per other areas women and recognizably LGBTQ streamers face harassment at a hugely disproportionate level [33][34]. In our observations this can occur both within and outside of the artistic context: some streamers were harassed over subject matter that others were not. In one example, a young female artist from Europe was continually harassed in chat about the 'over-sexualization' of her anime drawing, while other works (that were far more risqué by Western standards) by young men were not commented upon. Other streamers faced harassment based on physical appearance, accent, etc. as is typical of streaming in other contexts. Thus, the need of the streamer to continually monitor these outside channels, manage the protocol of the streams relative to real-time events when other activities are at the forefront of cognitive demand, and the need to engage in managing the inherent toxicity prevalent in the larger streaming community and platforms lead to some convergence in considerations of social demand, physical demand, and labor studies.

\subsection{Laboratory Experiments and Experimental Designs with Microstreaming Videogames}

Although not specifically designed to study selfidentified microstreamers, experimental research has examined how individuals engaging in ad hoc microstreaming are affected by the experience. Much of this work has been focused on the social demands of game streaming, owing to the centrality of sociality as a gratification of gaming [35][36]. Whether or not an audience is gathered synchronously or viewing an archived stream, the streamer's anticipation that there might be an audience is enough to make salient social and performative elements of the activity [37]. From a media psychological perspective, these social and performative elements are critical from the perspective of social facilitation theory [38], which posits that when in the presence of others, people increased their drive towards any given activity, which translates to increased effort. Although some argue that humans tend to avoid expending effort when possible (the cognitive miser approach; [39]), advances in cognitive psychology have demonstrated that oftentimes, individuals engage in activities specifically because they require effort - that the effort itself is a psychological reward for the activity itself [40]. Translating this to microstreaming and the social performance of one's hobbies and leisure activity, one implication is that the social demands resulting from the presence of others - albeit digitally - could be an additional source of effort that is both (a) intrinsically enjoyable and (b) could also improve performance.

Broadly, social facilitation efforts have been observed when playing video games in front of smaller audiences, such as "couch co-playing" [41]. In their 
study, research participants played the first-person shooter Quake III: Arena either alone or in front of two others. Participants played the game twice in separate 10-minute sessions, once in a lower and once in a higher difficulty setting (manipulating the skill levels of the computer-controlled opponents). When playing the lower difficulty game, players had higher scores when playing in front of others than when playing alone, although these effects did not replicate for the more difficult game. In other words, players tried harder when they were being watched even by a comparatively small audience (prior work has found that even a single observer can trigger social facilitation effects, see [42]), which translated into increased performance. This is similar to the way that the art streamers noted that one of the key aspects of streaming their creative process was an audience that required them to engage even on days when they were less inclined or motivated to do so.

Less clear is whether these findings would translate to a microstreaming scenario. Data from [43] found that individuals playing a third version of the videogame in an arena-style online mode (with an simulated online audience watching and commenting through the game's built-in text chat) performed slightly better than when playing alone, but not as well as when playing in front of co-located others. One explanation for the lack of effects in the "virtual audience" condition was that when this study was conducted (2009), streaming was not a widespread activity; another was that the text-chat might not have been salient to players largely not used to having others watch them play videogames online. To more directly test this, Watts et al [43] had participants play Call of Duty: Black Ops II either (a) alone, (b) while being watched by a live two-person Twitch audience, or (c) for later viewing by an asynchronous YouTube Gaming audience. They did not find streaming to be any more socially demanding than playing alone, despite being able to recall details of the stream dialogue, including jokes and teasing behaviors that the audiences engaged in during the gaming sessions. These findings seem to conflict claims that the social demands of microstreaming could be influencing gameplay. However, an alternative explanation offered was that the mostly novice players were more focused on the higher-than-expected cognitive demands of a (to them) difficult game (replicating 44]). Another explanation was that the audience dialogue was not frequent enough to trigger social demands, as the streaming audience members made only a handful of comments during gameplay (about two per minute).

Although microstreaming is a somewhat organic activity that could be difficult to analyze using experimental designs, a demand framework could help us understand the influence of online audiences on our leisure activities. For example, the studies above could be replicated by varying both the size of the audience and the frequency of their interactions to see when social demands are beneficial to (or might detract from) the streaming experience. Such studies could also be conducted with a focus on current microstreamers, either engaging them online or in laboratory settings. To better understand the extent to which streamers are able to split their attention between their focal activity and the audience's engagement with the activity, behavioral researchers could employ attention measurements such as eye-tracking devices [45]. Given how often that game streamers mentioned the rather steep learning curves associated with split attention (see Section 3.1), and current research demonstrating the impact of gaming on attention and cognition broadly [46], future research would benefit by a more specific focus on how microstreamers manage and are affected by the cognitive demands of this attention. Such work would be as relevant to streaming of other activities, especially if we consider that dynamics of flow theory would suggest that intrinsically motivating activities such as creative arts are often marked by intense attentional focus on the task at hand [47]. Here, microstreamers are a bit of a paradox in that they are engaging activities that require cognitive focus while at the same time, openly engaging and even embracing the additional efforts brought on by audiences.

Related to this, many microstreamers discussed how their own emotional reactions are directly impacted by the emotions expressed by audiences (see Section 3.1). From a media psychology perspective, the notion of intra-audience effects [48] is applicable here. It is plausible that mere exposure to the expressed emotional output of synchronous streaming audience can directly influence the streamer's own emotional reaction to their gameplay-so-called emotional contagion effects having been found with other media [49].

Finally, beyond the mere presence effects of streaming audiences, Cook [50] suggests that trolling behaviors are especially prevalent in online gaming environments, of which microstreaming could be included. While professional streamers might be more accustomed to being harassed by audiences (akin to professional athletes who are regularly face hostile fans), microstreamers more personally invested in their activities might struggle to cope with the social and emotional demands of hostile audiences - especially of hostilities directed at marginalized groups online [51].

\section{Analysis and Discussion}

Microstreaming is a growing activity, but has received comparatively little scholarly attention. In this manuscript, we explicate microstreamers as individuals 
who broadcast their hobbies to (a) small audiences and (b) more intrinsic than extrinsic motivation to stream. From this definition, we explored some of the motivations and effects of microstreaming on those hobbyists through the interactivity-as-demand framework. Ethnographic research on game streamers, a related analysis of art streamers, and a laboratorybased research into ad hoc microstreamers (individuals who engaged the activity for the first time) all found similar trends. As Consalvo et al. [52] have suggested, while video games are designed to be directly played rather than spectated, streaming services increasingly facilitate tandem play in which the gamer and the audience can collaborate and cooperate towards myriad gameplay outcomes. Microstreaming seems to exacerbate these trends in obvious fashion: given the small size of the streams, and the $1: 1$ or $1:$ few relationships between streamer and audience, the "tandem-nature" of these streams is quite different than the large, audience-en-masse as aggregate spectator notion that dominates traditional views of games as esports competitions. Indeed, given the scale factors, numerous observations across all three studies noted that the social demands of the audience can directly influence gameplay/activity, and can also encourage or even allow the player to experiment with different ingame choices.

The motivations of microstreamers are also intriguing, complex, and intertwined. The demand framework helps us connect across these different studies by allowing us to examine individually the cognitive, emotional, physical, and social demands across a range of activities. In each of these cases, the cognitive demands varied based on the activity being streamed but also via the motivations of the streamer engaged in the activity, and in particular their intrinsic motivation. Gamers streamed "for fun" or "as a way to destress" - artists streamed "for practice" or "to be a better artist"- but the majority of the microstreamers we examined across these contexts were driven by concerns outside of economic advancement, and were generally intrinsically motivated to engage with streaming in general. Similarly, the emotional demands of engagement were characterized by a mix of affective reactions to the activities themselves (the joy of gaming or painting) but also the additional work of regulating and engaging emotional reactions to elements of the streaming environment itself-from the interfaces to the conversations to the mere presence or presumed evaluations of others. When considering the physical demand of these activities, similarities emerged in consideration of the grueling nature of streaming in general, and the way that the platform incentivizes long streams and less-than-casual engagement was a core concern of microstreamers, as were the unwritten (but not unfelt) requirements of appearance, dress, practice, and more. In addition, the physicality of the given activities was highlighted as streamers noted the dexterity and focus needed to engage with their myriad subjects. Lastly the social demands were a key area of convergence given the small nature of these streams, as the ability of the audience to influence the streamer and vice-versa was a key highlight, and points to the potential of small streams as co-creative nuclei. That said, issues of toxicity, harassment, and discrimination were also in some sense amplified in turn.

One additional consideration in this research relates to the dramatic increases in online traffic and subsequent online behaviors and interactions during a time of social distancing. Popular social media pages, media streaming companies, and live-streaming platforms have seen dramatic increases during the novel coronavirus outbreak-Twitch for example experiencing a nearly $20 \%$ spike in traffic [53]. For microstreamers, these findings suggest a possible uptick in traffic towards their streams, as well as an increased desire to stream/narrate mundane activities as a means to cope with lockdown/confinement given emergency stay-at-home orders for large segments of the population. One potential line of research might consider analyzing how sudden increases in streaming traffic - especially if they come from new viewers (i.e., outside of one's own social network) - might be influencing streaming demands, and in particular the small and potentially tight-knit audiences we observed. Future work might consider microstreaming from additional theoretical viewpoints including leisure studies [21], self-determination theory [54], or others that allow for viewing these activities through different lenses that explore the myriad of motivations and effects of microstreaming.

\section{Conclusion}

Microstreamers represent a growing phenomenon of participatory online behaviors - in some ways, engaging many of the same "create and collaborate" behaviors central to the development of the internet as we understand it today. They are both similar to other streaming types found on popular platforms such as Twitch, but also a unique niche unto themselves. Microstreamers are often engaged via very different motivations and goals than larger, more popular streamers and personalities. They can exhibit a much more casual attitude towards their engagement with streaming, and yet despite this are passionate and deeply driven in their microcommunities, and often burn out or otherwise come-and-go from their channels as other concerns and motivations take precedence. Given the 
multiple styles, motivations, and activities explored throughout this paper, we suggest that labor analysis is not the only model by which to examine the activities of these individuals and their audiences, and that a demand framework is of increasing utility in understanding the nuances of microstreaming communities.

\section{References}

[1] S. Khamis, L. Ang, and R. Welling. "Self-branding, 'micro-celebrity' and the rise of Social Media Influencers," Celebrity Studies, 8, 2, 191-208. (April 2017) DOI:https://doi.org/10.1080/19392397.2016.1218292 [2] T. L. Taylor. Raising the stakes: e-sports and the professionalization of computer gaming. MIT Press, Cambridge, Mass. (2012)

[3] E. Witkowski, B. Hutchins, and M. Carter. "E-sports on the rise?: Critical considerations on the growth and erosion of organized digital gaming competitions," Proceedings of The 9th Australasian Conference on Interactive Entertainment Matters of Life and Death - IE '13, ACM Press, Melbourne, Australia, 1-2. (2013) DOI:

https://doi.org/10.1145/2513002.2513008

[4] M. Consalvo, M. Lajeunesse and A. Zanescu, "The authenticity engine: Livestreaming on Twitch," Proceedings of DiGRA 2020, Digital Games Research Association, Tampere, Finland (2020).)

[5] R. M. Ryan and E. L. Deci. "Intrinsic and Extrinsic Motivations: Classic Definitions and New Directions," Contemporary Educational Psychology, 25, 1, 54-67. (January 2000) DOI: https://doi.org/10.1006/ceps.1999.1020 [6] J. Woodcock and M. R. Johnson. "The Affective Labor and Performance of Live Streaming on Twitch.tv,"

Television \& New Media 20, 8, 813-823. (December, 2019) DOI:https://doi.org/10.1177/1527476419851077

[7] Bonnie Ruberg, Amanda L. L. Cullen, and Kathryn Brewster. 2019. Nothing but a "titty streamer": legitimacy, labor, and the debate over women's breasts in video game live streaming. Critical Studies in Media Communication 36, 5 (October 2019), 466-481.

DOI:https://doi.org/10.1080/15295036.2019.1658886

[8] William Clyde Partin. 2019. Watch Me Pay: Twitch and the Cultural Economy of Surveillance. SS 17, 1/2 (March 2019), 153-160.

DOI:https://doi.org/10.24908/ss.v17i1/2.13021

[9] Austin Walker. 2014. Watching Us Play: Postures and Platforms of Live Streaming. SS 12, 3 (June 2014), 437-442. DOI:https://doi.org/10.24908/ss.v12i3.5303

[10] T. Faas, L. Dombrowski, E. Brady, and A. Miller. "Looking for Group: Live Streaming Programming for Small Audiences," Information in Contemporary Society, N. G.

Taylor, C. Christian-Lamb, M. H. Martin and B. Nardi (eds.). Springer International Publishing, Cham, 117-123. (2019) DOI:https://doi.org/10.1007/978-3-030-15742-5_10 [11] Nancy K. Baym. 2015. Connect With Your Audience! The Relational Labor of Connection. The Communication Review 18, 1 (January 2015), 14-22.

DOI:https://doi.org/10.1080/10714421.2015.996401
[12] Brooke Erin Duffy. 2016. The romance of work: Gender and aspirational labour in the digital culture industries. International Journal of Cultural Studies 19, 4 (July 2016), 441-457.

DOI:https://doi.org/10.1177/1367877915572186

[13] Crystal Abidin. 2016. Visibility labour: Engaging with Influencers' fashion brands and \#OOTD advertorial campaigns on Instagram. Media International Australia 161, 1 (November 2016), 86-100.

DOI:https://doi.org/10.1177/1329878X16665177

[14] Elizabeth Wissinger. 2016. Glamour labour in the Age of Kardashian. Critical Studies in Fashion \& Beauty 7, 2 (December 2016), 141-152.

DOI:https://doi.org/10.1386/csfb.7.2.141_1

[15] Sonia Fizek, Fuchs Mathias, and Karin Wenz. 2020.

DIGITAL CULTURE \& SOCIETY 2019: laborious play and playful work. Digital Culture \& Society 5, 2 (2020).

[16] N. D. Bowman (Ed.). Video games: a medium that demands our attention. Routledge, New York, NY. (2018)

[17] N. D. Bowman. "Editorial: Video Games as Demanding Technologies," Media and Communication 7, 4, 144.

(December 2019)

DOI:https://doi.org/10.17645/mac.v7i4.2684

[18] J. Steuer. "Defining Virtual Reality: Dimensions

Determining Telepresence," Journal of Communication, 42, 4, 73-93. 1992. (December 1992)

DOI:https://doi.org/10.1111/j.1460-2466.1992.tb00812.x

[19] N. Bowman "Video Gaming as Co-Production," Video Gaming as Co-Production, R. Lind (ed.), Peter Lang. pp. 107-123. (2016)

[20] M. Wellenreiter. "Screenwriting and authorial control in narrative video games," Journal of Screenwriting, 6, 3, 343361. (September 2015)

DOI:https://doi.org/10.1386/josc.6.3.343_1

[21] R. Stebbins. "Serious Leisure," A Handbook of Leisure Studies, C. Rojek, S. Shaw \& A.J. Veal (eds.), New York:

Palgrave MacMillan, 448-458. (2006)

[22] B. Ruberg. "Obscene, pornographic, or otherwise objectionable: Biased definitions of sexual content in video game live streaming," New Media \& Society. (May 2020) 146144482092075.

DOI:https://doi.org/10.1177/1461444820920759

[23] T. L. Taylor. Watch me play: Twitch and the rise of game live streaming, Princeton University Press, Princeton; Oxford. (2018)

[24] M. Consalvo and A. Phelps. "Performing Game Development Live on Twitch," Proceedings of the 52rd

Hawaii International Conference on System Sciences, Maui, Hawaii. pp. 2348-2447. (2019)

DOI:https://doi.org/10.24251/HICSS.2019.294

[25] A. Phelps and M. Consalvo. "Laboring Artists: Art Streaming on the Videogame Platform Twitch," Proceedings of the 53rd Hawaii International Conference on System Sciences. Maui, Hawaii. 2677-2687. (2020)

DOI:https://doi.org/10.24251/HICSS.2020.326

[26] M. B. Holbrook and E. C. Hirschman. "The Experiential Aspects of Consumption: Consumer Fantasies, Feelings, and Fun," Journal of Consumer Research, 9, 2, 132-140. (1982) [27] J. H. Stohs. "Intrinsic motivation and sustained art activity among male fine and applied artists," Creativity 
Research Journal, 5, 3, 245-252. (January 1992) DOI:https://doi.org/10.1080/10400419209534438 [28] S. M. Rostan. "Studio Learning: Motivation, Competence, and the Development of Young Art Students' Talent and Creativity," Creativity Research Journal, 22, 3 , 261-271. (August 2010)

DOI:https://doi.org/10.1080/10400419.2010.503533

[29] The Joy of Painting (TV Series 1983-1994) - IMDb. Retrieved July 9, 2020 from

http://www.imdb.com/title/tt0383795/

[30] P. Bright. "Twitch's Bob Ross marathon is the most beautiful thing the Internet has ever created," Ars Technica. (2015) Retrieved July 9, 2020 from

https://arstechnica.com/gaming/2015/11/twitchs-bob-rossmarathon-is-the-most-beautiful-thing-the-internet-has-evercreated/

[31] V. Huta and R. M. Ryan. "Pursuing Pleasure or Virtue: The Differential and Overlapping Well-Being Benefits of Hedonic and Eudaimonic Motives," Journal of Happiness Studies 11, 6, 735-762. (December 2010)

DOI:https://doi.org/10.1007/s10902-009-9171-4

[32] T. Scholz. FCJ-013 "It's New Media: But is it Art Education?," The Fibreculture Journal. (2004) Retrieved July 9, 2020 from http://three.fibreculturejournal.org/fcj-013its-new-media-but-is-it-art-education/

[33] J. Cai and D. Y. Wohn. "What are Effective Strategies of Handling Harassment on Twitch?: Users' Perspectives," Conference Companion Publication of the 2019 on Computer Supported Cooperative Work and Social Computing, ACM, Austin TX USA, 166-170. (2019)

DOI:https://doi.org/10.1145/3311957.3359478

[34] T. Lorenz and K. Browning. "Dozens of Women in Gaming Speak Out About Sexism and Harassment," The New York Times. (2020) Retrieved July 9, 2020 from https://www.nytimes.com/2020/06/23/style/women-gamingstreaming-harassment-sexism-twitch.html

[35] J. L. Sherry, K. Lucas, B. S. Greenberg, and K. Lachlan. "Video game users and gratifications as predictors of use and game preference" in Playing video games: Motives, responses, and consequences, $\mathrm{P}$. Vorderer and $\mathrm{J}$. Bryant (eds.), Lawrence Erlbaum Associates, Mahweh, NJ, pp. 213224. (2006)

[36] R. Tamborini, N. D. Bowman, A. Eden, M. Grizzard, and A. Organ. "Defining media enjoyment as the satisfaction of intrinsic needs," Journal of Communication. Oxford University Press, Oxford UK, 2011, pp. 758-777. (2011). DOI: https://doi.org/10.1111/j.1460-2466.2010.01513.x [37] J-H. Lin., N. Bowman, S-F. Lin, and Y-S. Chen. "Setting the digital state: Defining game streaming as an entertainment experience," Entertainment Computing, Elsevier, New York. (2019) DOI :

https://doi.org/10.1016/j.entcom.2019.100309

[38] R.B. Zajonc. "Social facilitation," Science, AAAS, Washington DC, pp. 269-274. (1965) DOI: https:// https://doi.org/10.1126/science.149.3681

[39] S. T. Fiske and S. E. Taylor. "Social cognition," McGraw-Hill, New York City. (1991)

[40] M. Inzlicht, A. Shenhav, and C. Y. Olivola. "The effort paradox: Effort is both costly and valued," Trends in Cognitive Science, 22,4, 337-349. (February 2018) DOI: https://doi.org/10.1016/j.tics.2018.01.007
[41] N. D. Bowman, R. Weber, R. Tamborini, and J. L. Sherry. "Facilitating game play: How others affect performance at and enjoyment of video games," Media Psychology, 16,1, 39-64. (2013) DOI:

https://doi.org/10.1080/15213269.2012.742360

[42] J. Platania and G. P. Moran. "Social facilitation as a function of the mere presence of others," The Journal of Social Psychology, 141, 2, 190-197. (2001) DOI: https://doi.org/10.1080/00224540109600546

[43] Evan R. Watts, Kevin Koban, and Nicholas D. Bowman. 2021. Digital gaming audiences: Awareness, without closeness. Entertainment Computing 36, (January 2021), 100384. DOI:https://doi.org/10.1016/j.entcom.2020.100384 [44] N. Bowman, R. Weber, R. Tamborini, \& J. L. Sherry. "Facilitating Game Play: How Others Affect Performance and Enjoyment of Video Games," Default journal, 39-64. 2013. DOI: https://doi.org/10.1080/15213269.2012.742360 [45] A. T. Duchowski. "Eye tracking methodology", Springer, Cham Switzerland. (2017)

[46] F. Pallavicini, A. Ferrari, and F. Mantovani. "Video Games for Well-Being: A Systematic Review on the Application of Computer Games for Cognitive and Emotional Training in the Adult Population," Frontiers in Psychology, 9, (2018).

DOI:https://doi.org/10.3389/fpsyg.2018.02127

[47] M. Csikszentmihalyi. Flow: The psychology of optimal experience, Harper \& Row, New York. (2019)

[48] J. E. Hocking, D. G., Margreiter, and C. Hylton. "IntraAudience Effects: A Field Test," Human Communication Research. 3, 3, 243-249. (1977) DOI:

https://doi.org/10.1111/j.1468-2958.1977.tb00522.x

[49] E. L. Cohen, N. D. Bowman, and A. L. Lancaster. "R U with Some1? Using Text Message Experience Sampling to Examine Television Coviewing as a Moderator of Emotional Contagion Effects on Enjoyment," Mass Communication and Society, 19,2, 149-172. (2016) DOI:

https://doi.org/10.1080/15205436.2015.1071400

[50] C. L. Cook. "Between a troll and a hard place: The demand framework's answer to one of gaming's biggest problems," Media and Communication, 7, 4 (2019) DOI: http://doi.org/10.17645/mac.v7i4.2347

[51] P. R. Todd and J. Melancon "CyberPsychology Gender and Twitch," Cyberpsychology, Behavior, and Social Networking, 22, 7, 472-476 2019. DOI: https://doi.org/10.1089/cyber.2018.0560

[52] R. Scully-Blaker, J. Begy, M. Consalvo, and S. Ganzon. "Playing along and Playing for on Twitch: Livestreaming from Tandem Play to Performance," Proceedings of the 50th Hawaii International Conference on System Sciences. (2017) DOI:https://doi.org/10.24251/HICSS.2017.246

[53] E. Koeze and N. Popper. "The Virus Changed the Way We Internet," The New York Times. 2020. Retrieved July 9, 2020 from

https://www.nytimes.com/interactive/2020/04/07/technology/ coronavirus-internet-use.html

[54] E. L. Deci and R. M. Ryan. "Self-Determination Theory," Handbook of Theories of Social Psychology: Volume 1. SAGE Publications Ltd, 1 Oliver's Yard, 55 City Road, London EC1Y 1SP United Kingdom, 416-437. (2012) DOI:https://doi.org/10.4135/9781446249215.n21 